\title{
Robot-Assisted Technique for Total Gastrectomy and D2 Lymphadenectomy with Anomalous Vasculature
}

\author{
Courtney E. Barrows, MD¹, Ana Sofia Ore, MD¹, Jonathan Critchlow, $\mathrm{MD}^{2}$, and A. James Moser, MD, FACS ${ }^{1}$ \\ ${ }^{1}$ Pancreas and Liver Institute, Beth Israel Deaconess Medical Center/Harvard Medical School, Boston, MA; ${ }^{2}$ Department \\ of Surgery, Beth Israel Deaconess Medical Center, Boston, MA
}

\section{BACKGROUND}

Recent level 1 data indicate that minimally invasive gastrectomy achieves better short-term outcomes than open technique without compromising oncologic efficacy. The robotic technique of total gastrectomy exhibits particular utility for technically challenging resections of locally advanced lesions for which extended lymphadenectomy and vascular dissection are indicated. ${ }^{1}$

\section{METHODS}

The video demonstrates stepwise technical aspects of robot-assisted D2 total gastrectomy with hand-sewn Rouxen-Y esophagojejunostomy for advanced gastric adenocarcinoma after neoadjuvant systemic chemotherapy. The example in the video involved skeletonizing and preserving a large replaced left hepatic artery undetected by preoperative imaging. A retrospective review was performed with institutional review board (IRB) approval.

\section{RESULTS}

Between August 2013 and April 2017, 27 robot-assisted gastrectomies with D2 lymphadenectomy were performed for gastric cancer. The median patient age was 65 years (range

Electronic supplementary material The online version of this article (https://doi.org/10.1245/s10434-017-6304-6) contains supplementary material, which is available to authorized users.

(C) Society of Surgical Oncology 2018

First Received: 27 September 2017; Published Online: 12 February 2018

A. J. Moser, MD, FACS

e-mail: ajmoser@bidmc.harvard.edu
$39-83$ years), and $58 \%$ of the patients were male. The median body mass index was $26 \mathrm{~kg} / \mathrm{m}^{2}$ (range $18-40 \mathrm{~kg} / \mathrm{m}^{2}$ ). The median operative time was $463 \mathrm{~min}$ (range 169-853 min), with $100 \mathrm{ml}$ (range 10-1000 ml) of blood loss and no conversions, representing the entire institutional learning curve. In all 27 cases, R0 resection was achieved, and a median of 23 (range 11-47) lymph nodes were retrieved. The median hospital stay was 7 days (range $2-44$ days). Nine patients experienced clinically significant complications (Clavien-Dindo 2 or higher $^{2}$ ). No reoperations or deaths occurred within 90 days.

\section{CONCLUSION}

The video is a stepwise demonstration of minimally invasive total gastrectomy with hand-sewn Roux-en-Y esophagojejunostomy, extended lymphadenectomy, and preservation of hepatic arterial inflow using a robotic technique identical to its open counterpart.

ACKNOWLEDGMENT This study was supported by the John F. Fortney Charitable Pancreatic Cancer Research Group, the Alliance of Families Fighting Pancreatic Cancer, and the Greg and Cathy Griffith Family Foundation.

FUNDING SOURCES The John F. Fortney Charitable Pancreatic Cancer Research Group, the Alliance of Families Fighting Pancreatic Cancer, and the Greg and Cathy Griffith Family Foundation.

DISCLOSURE None.

\section{REFERENCES}

1. Manciu S, Dragomir M, Curea F, Vasilescu C. Robotic surgery: a solution in search of a problem: a Bayesian analysis of 343 robotic procedures performed by a single surgical team. J Laparoendosc Adv Surg Tech A. 2017;27:363-74.

2. Clavien PA, Sanabria JR, Strasberg SM. Proposed classification of complications of surgery with examples of utility in cholecystectomy. Surgery. 1992;111:518-26. 